Staff Paper Series 2008-04 November 2008

What factors determine the number of trading partners?

\author{
Noriaki Matsushima \\ Graduate School of Business Administration, Kobe University \\ and \\ Ryusuke Shinohara \\ Faculty of Economics, Shinshu University
}

Faculty of Economics

Shinshu University

Matsumoto 390-8621 Japan

Phone: +81-263-35-4600

Fax: +81-263-37-2344 


\title{
What factors determine the number of trading partners?*
}

\author{
Noriaki Matsushima ${ }^{\dagger}$ \\ Graduate School of Business Administration, Kobe University \\ Ryusuke Shinohara ${ }^{\ddagger}$ \\ Faculty of Economics, Shinshu University
}

November 20, 2008

\begin{abstract}
Most studies on buyer-supplier relationship have focused on the nature of interfirm relationships from the viewpoint of the assembler of managing suppliers as partners. The flip side of this relationship, that is, the supplier's customer strategy and performance, has rarely been considered or examined. The purpose of the paper is to provide a simple game theoretical model explaining buyer-supplier relationships and show what factors determine the number of trading partners. We investigate buyersupplier relationships from the viewpoint of suppliers. We show that when the supplier is able to determine the number of trading partners, the optimal number of trading partners is small for the supplier if the supplier's bargaining power with its trading partners is weak, the economy of scope concerning the supplier's variable costs is significant, and its sunk investment has a firm-specific nature. The result might be consistent with the formation of Japanese buyer-supplier networks.
\end{abstract}

Keywords: buyer, supplier, investment, economies of scope

JEL Classification codes: L14, M11

\footnotetext{
${ }^{*}$ We would like to thank Shingo Ishiguro, Hideshi Itoh, Shinsuke Kambe, Toshihiro Matsumura, Takashi Shimizu and the seminar participants at Contract Theory Workshop (Kwansei Gakuin University) and Law and Economics Workshop (Hitotsubashi University) for their helpful comments. Any errors are the responsibility of the authors.

${ }^{\dagger}$ Correspondence author: Noriaki Matsushima, Graduate School of Business Administration, Kobe University, 2-1 Rokkodai, Nada, Kobe, Hyogo, 657-8501, Japan. Phone: (81)-78-803-6981. Fax: (81)-78803-6977. E-mail: nmatsush@kobe-u.ac.jp

${ }^{\ddagger}$ Ryusuke Shinohara, Faculty of Economics, Shinshu University, 3-1-1 Asahi, Matsumoto, Nagano, 3908621, Japan. Phone: (81)-263-37-2951. Fax: (81)-263-37-2344. E-mail: ryusukes@shinshu-u.ac.jp
} 


\section{Introduction}

It is believed that Japanese suppliers tend not to increase the number of their trading partners and that $R \& D$ investments by Japanese firms are intensified because of the narrow relationships with suppliers. Along the line, many researchers have indicated that the keiretsu relationship enables firms to exchange richer information between Japanese manufacturers and their partially owned keiretsu suppliers (see, Asanuma (1989), Helper and Sako (1995), Dyer (1996), and the papers listed therein). For instance, Dyer (1996) mentions that Japanese automakers and their suppliers were more specialized than their U.S. counterparts and shows a high correlation between supplier specialization and automaker profitability.

On the other hand, Nobeoka et al. (2002) provide another viewpoint on the relationship between Japanese suppliers and the number of trading partners and show that a broader customer scope strategy should result in superior performance, primarily because of superior learning opportunities. They point out that the emphasis on cooperative assembler-supplier relationships and the notion of the keiretsu group sometimes lead to a misconception that there are exclusive relationships between assemblers and suppliers in the Japanese automobile industry. In reality, many suppliers sell their components to multiple competing automobile manufacturers, and automakers also buy most components from multiple suppliers. This contrasts with the notion that Japanese auto assemblers maintain a cooperative relationship with suppliers through a quasi-hierarchical industry structure.

Nishiguchi (1994, p. 115) also shows that it is a fallacy (especially outside Japan) that Japanese keiretsu firms do business only with those in the same keiretsu group. Calculating the data in Sato (1988, p. 121), Nishiguchi (1994) mentions that even in the Toyota keiretsu group (recognized as among the tightest), 41.7 percent of its affiliated firms (defined here as those that are more than 20 percent owned by Toyota) sold 40 80 percent of their products to outsiders. He also points out that patterns of "cross" ownership by "competing" parent firms, a common practice in the automotive industry, 
also complicated the classifications.

Nobeoka et al. (2002) especially emphasize that most studies on the buyer-supplier relationship have focused on the nature of interfirm relationships from the viewpoint of the assembler of managing suppliers as partners. The flip side of this relationship, that is, the supplier's customer strategy and performance, has rarely been considered or examined.

We provide a simple model to explain the strategies of suppliers. The setting of the model is as follows. Consider a situation in which there is one supplier and two buyers. The supplier can provide a good that is used by the two buyers; however, the buyers cannot produce the good on their own. In this situation, the supplier first decides whom to negotiate with. Second, the supplier invests in productive facilities for the good and at this stage, decides the amount of investment. Third, there are negotiations between the supplier and the buyer(s) who were designated by the supplier in the first stage. In this stage, we apply a simple Nash bargaining approach that was used by Chipty and Snyder (1999) and Raskovich (2003). The characteristic of this approach is that if the supplier chooses to bargain with the two buyers in the first stage, the supplier and each buyer negotiate simultaneously and separately. The supplier and each buyer conduct the Nash bargaining, assuming that it is also being conducted in the other bargaining. If the supplier's production cost is covered as a result of the bargaining, the supplier provides and sells the good to the buyer; otherwise, the good is not provided.

We show that when the supplier is able to determine the number of trading partners (one or two), the optimal number is one for the supplier if the supplier's bargaining power with its trading partners is weak, the supplier's sunk investment cost is large, and the economy of scope concerning variable costs incurred by the supplier is significant. As briefly discussed below, the relationship between the optimal number and the bargaining power may be consistent with the formation of Japanese buyer-supplier networks.

The bargaining power of the supplier plays a central role in our model, and we consider that the topic of bargaining processes is important in the discussion of buyer-supplier networks. As summarized by Nishiguchi (1994, p. 125), until the mid-1970s, nearly 50 
percent of the subcontractors surveyed reported that prices were "unilaterally determined" by their customers. In sharp contrast, in 1983, 83.4 percent of the respondents used "bilateral price agreements." In other words, until the mid-1970s, the bargaining power of these subcontractors was almost equal to zero, but in 1983, their bargaining power changed drastically. The dramatic changes in the negotiation processes may have affected the formation of buyer-supplier networks. This structural change in price negotiations occurred due to the following reason (Nishiguchi $(1994, \S 4)$ ): In order to manage the increasing complexity of products, in the 1960s, the Japanese major electronics and automobile firms began to delegate the assembly of finished products, the subassembly or manufacture of system components, and the subsystem manufacture to major subcontractors. The structural change in these industries led to the emergence of multi-skilled subcontractors and collaborative manufacturing in these subcontracting relationships. As a result, subcontractors engaged in cooperative investments with their buyers and the basic orientation of price negotiations shifted from bargaining between unequal partners to joint problem solving.

This paper is closely related to Chipty and Snyder (1999) and Raskovich (2003) and is a major extension of these papers. However, to analyze a buyer-supplier network with cooperative investments, we add two new elements to these papers. One is the seller's decision regarding the number of buyers, and the other is the seller's investment to improve the quality of the buyers' products. These elements are important in analyzing the Japanese buyer-supplier relationships that have been discussed by many researchers mentioned above.

This paper is related to the literature on the hold-up problem because the supplier's investment is not fully compensated by the buyers (a classic form of "hold-up"). The literature mainly discusses ways to overcome the hold-up problem (e.g., Klein et al. (1978) and Williamson (1979)) and deals with a pair of buyers and sellers in isolation, whereas this paper considers the hold-up problem in a network. ${ }^{1}$

\footnotetext{
${ }^{1}$ The other methods are changing ownership structure (e.g., Grossman and Hart (1986), Hart and Moore (1990), and Aghion and Bolton (1992)) and contractual solutions (e.g., Chung (1991) and Aghion et al.
} 
Konishi et al. (1996) formulate a bargaining model of buyer-seller relationships from the buyer's viewpoint. Their purpose is to provide an alternative solution for the hold-up problems in contrast to the vertical integration approach advocated by Grossman and Hart (1986) and Hart and Moore (1990). Although their model provides a plausible explanation as to why typical auto-assemblers in Japan do not vertically integrate a single parts supplier but transact with two potentially competitive suppliers, they do not explain suppliers' decisions on the number of buyers.

This paper is also related to the literature on buyer and seller networks. While there are many papers discussing buyer-seller networks (e.g., Kranton and Minehart (2000, 2001)) that compare vertically integrated firms and networks of manufacturers and suppliers, the purpose of this paper is different from those papers. ${ }^{2}$ Although in most of those papers, product quality is exogenously given, we discuss quality investment by the upstream supplier who anticipates the following negotiations between the buyers.

The remainder of this paper is organized as follows. Section 2 presents the basic model. Section 3 presents the main result. Section 4 extends the basic model. Section 5 concludes the paper.

\section{$2 \quad$ A simple model}

We consider a situation in which there is one supplier and two potential buyers (buyers 1 and 2). For example, in the case of the automobile industry, the supplier corresponds to an auto parts manufacturer and the buyers correspond to automotive manufacturers. The supplier can produce a good and sell it to the buyers. Although the buyers need one (1994)). Che and Hausch (1999), however, showed that when investments have a cooperative nature (e.g., the seller's investment improves the buyer's valuation of the good), contracting has no value if committing not to renegotiate the contract is impossible (see also Hart and Moore (1999) and Segal (1999)). This paper also has a cooperative nature because the supplier's investment improves the quality of buyers' products. Using a spatial competition model, Matsushima $(2004,2008)$ consider buyer-supplier networks with the hold-up problem. In those papers, however, quality investments implemented by upstream suppliers are not considered.

2 Jackson and Wolinsky (1996) and Bala and Goyal (2000) provided formal models of network formation. Belleflamme and Bloch (2004), Billand and Bravard (2004), Goyal and Joshi (2006), and Furusawa and Konishi (2007) applied the theory to the models of oligopoly. 
unit of the good, they cannot produce it on their own, and therefore, they must buy the good from the supplier.

We model the negotiation between the supplier and the buyers as the following threestage game: In the first stage, the supplier decides whom to negotiate with. In the second stage, the supplier determines the amount of investment and in the third stage, the supplier and the buyers that were designated in the first stage negotiate. If the negotiation is successful, the supplier produces the good and sells it to the buyer. Otherwise, the good is not provided and the buyer obtains nothing.

We now explain the details of the second and third stages.

In the second stage, if the supplier invests $K \geq 0$ and the number of its negotiation partners is one (two), the cost of the investments is $c K^{2}\left(d K^{2}\right.$, respectively), where $d \in$ $[c, 2 c]$ and $K$ is each buyer's evaluation for its input. This investment cost is assumed to be sunk, that is, the supplier cannot recover the cost in the third stage. This assumption means that the per buyer (sunk) investment cost is smaller when the supplier trades with two partners than when it trades with only one partner, and that the investment cost is related to several kinds of sunk set-up costs; for instance, making a grand design for the input of partners, conducting basic surveys to make the grand design, and building firm-specific facilities to make those inputs.

In the third stage, we consider a sort of bilateral and simultaneous negotiation. If the supplier negotiates with two buyers, then it enters into simultaneous bargaining with each of the two buyers separately. ${ }^{3}$ The bargaining determines whether one unit of the good is provided and how much money the buyer transfers to the supplier. For each bargaining, if the bargaining is successful, then one unit of the good is provided. The cost of providing the good is $K^{2}$ if one unit of the good is produced, and $a K^{2}$ if two units of the good are produced, where $a \in[1,2]$ and this cost is not a sunk cost. These assumptions mean that the per buyer production cost is smaller when the supplier trades with two partners

\footnotetext{
${ }^{3}$ Some people may assume that the results in the paper depend on the simultaneous bargaining procedure. Fortunately, the results in a sequential bargaining are similar to those in the simultaneous bargaining. We show them in the Appendix.
} 
than when it trades with only one partner, and that this cost is related to several kinds of variable costs; for example, material, labor, and natural resources. ${ }^{4}$

We have implicitly assumed that the supplier cannot supply to more than two buyers. This constraint reflects technological difficulties of the suppliers. For instance, using a common platform, Nissan (a Japanese major automobile manufacturer) produces two brands of cars (CUBE and MARCH). It is not easy, however, for Nissan to make a new type of car under the common platform because it restricts the car's design, size, drivability, and so on. ${ }^{5}$ Therefore, we consider that the implicit assumption is reasonable.

Payoffs to the supplier and the two buyers are determined as follows: Let $K$ denote the amount of investment in the second stage. If buyer $i$ obtains the good and pays $T_{i}$, then it receives the payoff $K-T_{i}$, in which $K$ can be interpreted as a benefit from the good that is assumed to be common to all buyers. Otherwise, its payoff is zero. When the supplier negotiates with the two buyers, the supplier's payoff is $T_{1}+T_{2}-a K^{2}-d K^{2}$ if the supplier successfully negotiates with buyers 1 and $2, T_{i}-K^{2}-d K^{2}$ if the supplier succeeds only in the negotiation with buyer $i(i=1,2)$, and $-d K^{2}$ if none of the bargainings are successful. When the supplier negotiates with one buyer, the supplier's payoff is $T_{i}-K^{2}-c K^{2}$ if the bargaining with the buyer is successful and $-c K^{2}$ otherwise.

Note that, in the model, we consider that the transaction between the buyer and the supplier can be interpreted as a reduced form of the following situation. Suppose that the buyer faces demands by anonymous consumers, its production technologies, and so on. The quality of the input is crucial for the quality of the final product. The consumers' demands indirectly depend on the quality of the input. The buyer engages in the procurement

\footnotetext{
${ }^{4}$ If some prices of widgets to produce the buyer's inputs depend on the following functional form, the assumption that $a \in[1,2]$ is reasonable: $F / Q+w$, where $F(>0)$ and $w(>0)$ are exogenous parameters and $Q$ is the quantity demanded by the supplier. That price schedule is often called quantity discount (Jeuland and Shugan (1983)). The price schedule is equivalent to the case in which the total payment for widgets is equal to $F+w Q(=Q \times(F / Q+w))$, the so-called "two-part tariff."

${ }^{5}$ Some researchers also point out that this kind of component sharing has a trade-off: the benefit is a cost reduction in designing and purchasing additional components, but the cost is an increase in mismatch costs associated with using existing components with excess capability (Fisher et al. (1999), Ramdas and Sawhney (2001)).
} 
negotiation with the supplier and determines a non-linear pricing contract for the supply of the input. Based on the contract terms, the buyer determines its quantity of input.

We assume that the outcome of the third stage is determined as follows:

1. The outcome of each negotiation is given by the Nash bargaining solution under the belief that the outcome of the other bargaining is also determined according to the Nash bargaining solution.

2. The joint surplus is divided among the buyer and the supplier in the proportion of one part to $\beta>0$, in which $\beta$ represents the bargaining power of the supplier, and the supplier is more advantageous than the buyer in the bargaining if and only if $\beta>1$.

In this model, there is an externality among bargainings. Although each bargaining decides whether one unit of the good is produced so as to maximize joint surplus, the cost of providing the good depends on the outcome of the other bargaining. The cost of the good is $(a-1) K^{2}$ if the other negotiation is successful, and $K^{2}$ otherwise. Thus, the joint surplus of each bargaining varies according to the belief about the other bargaining. Note that, in this assumption, two participants in each bargaining (the supplier and one buyer) believe that the other bargaining is conducted efficiently and this belief comes true in equilibrium.

\section{Analysis}

We solve the three-stage model using backward induction. First, we calculate the Nash bargaining outcomes of the third stage. Second, we go back to the second stage and derive optimal investment levels for the supplier. Finally, we consider the first stage and examine the number of buyers it is optimal for the supplier to negotiate with.

\subsection{The second and third stages}

We need to consider the following two cases: the case in which the supplier negotiates with only one buyer, and the case in which the supplier negotiates with two buyers. 


\subsubsection{Negotiation with one supplier and one buyer}

If the supplier decided to negotiate with one buyer and investigated $K \geq 0$ in the second stage, then the surplus of this negotiation is $K-K^{2}$. Let $T$ denote a payment from the buyer to the supplier. The buyer and the supplier split the surplus in a way that satisfies $K-T: T-K^{2}=1: \beta$. Therefore, we obtain

$$
\beta[K-T]=T-K^{2} \text { or } T=\frac{\beta K+K^{2}}{1+\beta} .
$$

Then, the profit of the supplier is

$$
\begin{aligned}
\pi_{1}=T-K^{2}-c K^{2} & =\frac{\beta K+K^{2}}{1+\beta}-K^{2}-c K^{2} \\
& =\frac{\beta K-(\beta+(1+\beta) c) K^{2}}{1+\beta} .
\end{aligned}
$$

Now, we go back to the second stage, taking $\pi_{1}$ as above. Then, the amount of investment that maximizes the supplier's profit is

$$
K_{1}=\frac{\beta}{2(\beta+c+\beta c)},
$$

by the first-order condition. Hence, the seller invests $K_{1}$ when it negotiates with one buyer in the second stage. The maximized profit of the supplier is

$$
\pi_{1}^{*}:=\frac{\beta^{2}}{4(1+\beta)(\beta+c+\beta c)},
$$

and the profit of the buyer who negotiated with the supplier is

$$
\pi_{1}^{b}:=\frac{\beta(\beta+2(1+\beta) c)}{4(1+\beta)(\beta+(1+\beta) c)^{2}} .
$$

The total profit of the production relationship is

$$
\pi_{1}^{*}+\pi_{1}^{b}:=\frac{\beta(\beta+(2+\beta) c)}{4(\beta+(1+\beta) c)^{2}} .
$$

\subsubsection{Negotiation with one supplier and two buyers}

Let us consider a case in which the supplier and two buyers negotiate. In this case, we need to consider two possibilities. One is the possibility that each buyer pays not less than 
$K^{2}$ and the other is that each buyer pays less than $K^{2}$ and the sum of the payments of the two buyers is greater than $a K^{2}$. In the first case, one unit of the good can be provided and the buyer in the successful negotiation can obtain the good even if the other bargaining breaks down. In this situation, the buyer is non-pivotal to the production of two units of the good. In the other case, if one of the buyers withdraws from the negotiation, then none of the goods are provided. In this situation, each buyer is pivotal to the provision of the two units of the good (the term "pivotal" is used in Raskovich (2003)).

Non-pivotal buyers First, we consider a situation in which the two buyers are nonpivotal to the investment: the investment is successful even if one of the buyers withdraws from the negotiation. In this situation, the buyer and the supplier split the surplus $K-$ $(a-1) K^{2}$, where the first (resp. the second) term is the additional benefit (resp. cost) from the trade given that one trade will be executed. The buyer pays $T$ to the supplier in a way that satisfies

$$
\beta(K-T)=T-(a-1) K^{2} \text { or } T=\frac{\beta K+(a-1) K^{2}}{1+\beta} .
$$

The profit of the supplier is

$$
\pi_{2 n}=2 T-a K^{2}-d K^{2}=\frac{2 \beta K+2(a-1) K^{2}}{1+\beta}-a K^{2}-d K^{2} .
$$

The amount of the investment that maximizes it is

$$
K_{2 n}=\frac{\beta}{(1+\beta)(a+d)-2(a-1)} .
$$

Substituting $K_{2 n}$ into $T=\left(\beta K+(a-1) K^{2}\right) /(1+\beta)$, we obtain:

$$
T_{2 n}:=\frac{\beta^{2}(1+\beta a+(1+\beta) d)}{(1+\beta)((1+\beta)(a+d)-2(a-1))^{2}} .
$$

Since the buyers are non-pivotal, we must have $T_{2 n}-\left(K_{2 n}\right)^{2}>0$. Subtracting $\left(K_{2 n}\right)^{2}$ from $T_{2 n}$, we obtain

$$
T_{2 n}-\left(K_{2 n}\right)^{2}=\frac{\beta^{2}((a-1) \beta+d(1+\beta))}{(1+\beta)((1+\beta)(a+d)-2(a-1))^{2}},
$$

which is positive because $a>1$. In any case, every buyer is not pivotal at $K_{2 n}$. 
Substituting $K_{2 n}$ into $K$ in (6), we obtain the profit of the supplier

$$
\pi_{2 n}^{*}:=\frac{\beta^{2}}{(1+\beta)((1+\beta)(a+d)-2(a-1))} .
$$

The profit of each buyer is

$$
\pi_{2 n}^{b}=K-T=\frac{\beta((1+\beta)(1+d)-(a-1))}{(1+\beta)((1+\beta)(a+d)-2(a-1))^{2}} .
$$

The sum of the profits is

$$
\pi_{2 n}^{*}+2 \pi_{2 n}^{b}=\frac{\beta((2+\beta)(a+d)-4(a-1))}{((1+\beta)(a+d)-2(a-1))^{2}} .
$$

Pivotal buyers Second, we consider a case in which every buyer is pivotal to the investment. In this case, the investment fails if one of the two buyers withdraws from the negotiation.

If $T_{1}$ and $T_{2}$ designate payments from buyers 1 and 2 , respectively, the surplus of the bargaining with buyer 1 is $\left(K-T_{1}\right)+\left(T_{1}+T_{2}-a K^{2}\right)=K+T_{2}-a K^{2}$ and that of the bargaining with buyer 2 is $\left(K-T_{2}\right)+\left(T_{1}+T_{2}-a K^{2}\right)=K+T_{1}-a K^{2}$. In each equation, the terms between the first parentheses are the buyer's benefit from the trade and those between the second parentheses are the seller's benefit from the trade, given that the other trade will be executed. The buyers and the supplier split the surplus in a way that satisfies the following conditions:

$$
\begin{aligned}
& \beta\left[K-T_{1}\right]=T_{1}+T_{2}-a K^{2}, \text { and } \\
& \beta\left[K-T_{2}\right]=T_{1}+T_{2}-a K^{2} .
\end{aligned}
$$

Hence, we obtain

$$
T_{1}=T_{2}=\frac{\beta K+a K^{2}}{2+\beta}
$$

The profit of the supplier is

$$
\pi_{2 p}=T_{1}+T_{2}-a K^{2}-d K^{2}=\frac{2 \beta K-(a \beta+(2+\beta) d) K^{2}}{2+\beta} .
$$

This is maximized at

$$
K^{* *}=\frac{\beta}{a \beta+(2+\beta) d} .
$$


The profit of the supplier at $K^{* *}$ is

$$
\pi_{2 p}:=\frac{\beta^{2}}{(2+\beta)(\beta a+(2+\beta) d)} .
$$

The profit of each buyer at $K^{* *}$ is

$$
\pi_{2 p}^{b}:=K^{* *}-T_{i}=\frac{\beta(\beta a+2(2+\beta) d)}{(2+\beta)(\beta a+(2+\beta) d)^{2}} .
$$

The sum of the profits at $K^{* *}$ is

$$
\pi_{2 p}+2 \pi_{2 p}^{b}:=\frac{\beta(\beta a+(4+\beta) d)}{(\beta a+(2+\beta) d)^{2}} .
$$

Since every buyer is pivotal, the supplier invests in a way that maximizes (7) subject to $T_{i} \leq K^{2}$ for every buyer $i$, that is, ${ }^{6}$

$$
T_{1}=T_{2}=\frac{\beta K+a K^{2}}{2+\beta} \leq K^{2} \text { or } K \geq \frac{\beta}{2+\beta-a} .
$$

$K^{* *}$ satisfies the inequality if and only if

$$
\beta \leq \frac{2-a-2 d}{a-1+d}
$$

and then the supplier's profit is $\pi_{2 p}$. Otherwise, the supplier's payoff is maximized at $\widetilde{K}=\beta /(2+\beta-a)$ and the supplier's profit is

$$
\widetilde{\pi}_{2 p}=\frac{2\left(\beta \widetilde{K}+a \widetilde{K}^{2}\right)}{2+\beta}-a \widetilde{K}^{2}-d \widetilde{K}^{2}=\frac{(2-a-d) \beta^{2}}{(2-a+\beta)^{2}} .
$$

Remark 1 Note that $T_{1}+T_{2} \geq a K^{2}$ must also be satisfied at the optimal amount of investments; otherwise, two units of the good are not provided. Since $T_{1}=T_{2}=(\beta K+$ $\left.a K^{2}\right) /(2+\beta)$, we need to check whether $2\left(\beta K+a K^{2}\right) /(2+\beta) \geq a K^{2}$. That is, we now check whether $K^{* *}$ and $\widetilde{K}$ satisfy $\beta K(2-a K) \geq 0$. Since $K^{* *}$ and $\widetilde{K}$ are positive, the two investment levels need to satisfy $2-a K \geq 0$. Replacing $K$ in $2-a K$ by $K^{* *}$ and $\widetilde{K}$ gives

$$
\begin{aligned}
& 2-a K^{* *}=\frac{a \beta+2(2+\beta) d}{a \beta+(2+\beta) d}>0, \text { and } \\
& 2-a \widetilde{K}=\frac{(2+\beta)(2-a)}{2+\beta-a} \geq 0 .
\end{aligned}
$$

Therefore, $T_{1}+T_{2} \geq a K^{2}$ holds at $K^{* *}$ and $\widetilde{K}$.

\footnotetext{
${ }^{6}$ We assume that no goods are provided if $T_{1}=T_{2}=K^{2}$.
} 
The profit of the supplier is summarized as follows:

$$
\pi_{2 p}^{*}= \begin{cases}\pi_{2 p} & \text { if } \beta \leq \frac{2-a-2 d}{a-1+d}, \\ \tilde{\pi}_{2 p} & \text { if } \beta \geq \frac{2-a-2 d}{a-1+d} .\end{cases}
$$

We now compare the case of pivotal and that of non-pivotal buyers and induce the maximized profit of the supplier when it negotiates with two buyers. For this, we need to compare $\pi_{2 n}^{*}$ with $\pi_{2 p}^{*}$. From some calculus, we obtain that

$$
\pi_{2 n}^{*}-\widetilde{\pi}_{2 p}=\frac{\beta^{2}((a-1) \beta+d(\beta+1))^{2}}{(a-2-\beta)^{2}(1+\beta)(2-a+d+a \beta+d \beta)}>0
$$

and

$$
\begin{aligned}
\pi_{2 n}^{*}-\pi_{2 p}=\frac{(2 \beta(a-1+d)-(2-a-3 d)) \beta^{2}}{(1+\beta)(2+\beta)(2-a+d+a \beta+d \beta)(2 d+a \beta+d \beta)} & \lesseqgtr 0 \\
\text { if and only if } \beta & \lesseqgtr \frac{2-a-3 d}{2(a-1+d)} .
\end{aligned}
$$

From (8), (9), and (10), $\pi_{2 p} \geq \pi_{2 n}^{*}$ if and only if $\beta \leq(2-a-2 d) /(a-1+d)$ and $\beta \leq(2-a-3 d) / 2(a-1+d)$; otherwise, $\pi_{2 n}^{*}$ is the largest among the three: $\pi_{2 n}^{*}, \pi_{2 p}$, and $\tilde{\pi}_{2 p}$. The maximized payoff of the supplier is summarized in Proposition 1.

Proposition 1 Let $\pi_{2}^{*}$ denote the maximized profit when the supplier negotiates with two buyers. It is denoted by

$$
\pi_{2}^{*}= \begin{cases}\pi_{2 p} & \text { if } \beta \leq \min \left[\frac{2-a-3 d}{2(a-1+d)}, \frac{2-a-2 d}{a-1+d}\right] \equiv H, \\ \pi_{2 n}^{*} & \text { otherwise }\end{cases}
$$

The investment level of the supplier is $K^{* *}$ if $\beta \leq H$, otherwise $K_{2 n}$.

Note that $H=(2-a-3 d) /(2(a-1+d))$ if and only if $2-a-d \geq 0$, otherwise $H=(2-a-2 d) /(2(a-1+d))<0$, that is, $\pi_{2}^{*}=\pi_{2 n}^{*}$ for any $\beta$.

We now briefly mention the mechanism behind Proposition 1. The monetary transfer from each buyer to the supplier is crucially dependent on whether each of the buyers is pivotal. If they are not pivotal buyers, each of them has to compensate only the additional cost from its additional trade $(a-1) K^{2}$. As the value of a decreases (as the economy of 
scope concerning the supplier's variable costs becomes significant), the compensation by the buyers decreases. If they are pivotal buyers, each of them has to compensate the total cost from their trade $a K^{2}$ cooperatively. However, each buyer does not have to pay as much for the gross benefit from its trade $K$ because the buyers are able to pay for their benefits cooperatively. These properties are reflected in the denominator of the per buyer payment in which they are pivotal, $T_{1}=T_{2}=\left(\beta K+a K^{2}\right) /(2+\beta)$. The payment is quite different from that in which they are not pivotal, $T=\left(\beta K+(a-1) K^{2}\right) /(1+\beta)$. If the bargaining power is weak, the compensation of its production costs is important for the supplier, because it is difficult to take the gross benefit from the trades $(\beta K /(1+\beta)$ in the non-pivotal case, $\beta K /(2+\beta)$ in the pivotal case). Therefore, when the value of $a$ is small and the bargaining power is weak, the supplier chooses $K^{* *}$, which is larger than $K_{2 n}$ and then the buyers become pivotal buyers if $2-a-d \geq 0$.

Remark 2 One may consider using the Shapley value (Shapley, 1953) instead of the Nash bargaining solution for calculating outcomes of the bargaining between the supplier and the buyer in our framework. When the Shapley value is used in the third stage, each bargaining between the supplier and the buyer distributes its worth according to the Shapley value, given that the other bargaining also shares its surplus by following the Shapley value. However, in our model, the Nash bargaining outcomes of our model contain the outcome of the standard Shapley value, and the Nash bargaining outcomes correspond to the weighted Shapley value when the buyers' weight is 1 and the supplier's weight is $\beta .^{7}$ Therefore, our results do not change when the Shapley bargaining is conducted in the buyer-supplier negotiations.

\subsection{The first stage}

We now consider the supplier's choice concerning the number of buyers. Suppose that the supplier chooses the number to maximize its own profit. Then, the supplier negotiates

\footnotetext{
${ }^{7}$ In the standard Shapley value, the weight of the supplier and that of the buyers are equal to one. The weighted Shapley value generalizes the standard Shapley value in a way that allows that the weights of players take any positive value. See Kalai and Samet (1987) for details.
} 
with one buyer if and only if $\pi_{1}^{*} \geq \pi_{2}^{*}$.

To simplify the analysis, we consider two cases: (1) $2-a-d \geq 0$; (2) $2-a-d \leq 0$. We first consider the case of $2-a-d \geq 0$. In this case, the difference between $\pi_{1}^{*}$ and $\pi_{2}^{*}$ is

$$
\pi_{1}^{*}-\pi_{2}^{*}=\left\{\begin{array}{c}
\frac{\beta^{2}\left(4(d-c)-2(2-a+4 c-2 d) \beta-(4-a+4 c-d) \beta^{2}\right)}{4(1+\beta)(2+\beta)(\beta+(1+\beta) c)(\beta a+(2+\beta) d)} \\
\text { if } \beta<\frac{2-a-3 d}{2(a-1+d)}, \\
\frac{\beta^{2}(2-a-4 c+d-(4-a+4 c-d) \beta)}{4(1+\beta)(\beta+(1+\beta) c)((1+\beta)(a+d)-2(a-1))} \\
\text { otherwise. }
\end{array}\right.
$$

We clarify conditions under which $\pi_{1}^{*} \geq \pi_{2}^{*}$ holds. In the case of $\beta<(2-a-3 d) / 2(a-$ $1+d), \pi_{1}^{*} \geq \pi_{2}^{*}$ if and only if $4(d-c)-2(2-a+4 c-2 d) \beta-(4-a+4 c-d) \beta^{2} \geq 0$. Solving the inequality, we obtain the condition for $\pi_{1}^{*} \geq \pi_{2}^{*}:{ }^{8}$

$$
0<\beta \leq \min \left\{\frac{2-a-3 d}{2(a-1+d)}, \frac{-(2-a+4 c-2 d)+\sqrt{(2-a)^{2}+4(d-a) c+8 d}}{4-a+4 c-d}\right\} .
$$

We can similarly derive a condition for $\pi_{1}^{*} \geq \pi_{2}^{*}$ in the case of $\beta \geq(2-a-3 d) / 2(a-1+d)$ as follows:

$$
\frac{2-a-3 d}{2(a-1+d)} \leq \beta \leq \frac{2-a-4 c+d}{4-a+4 c-d} .
$$

In the case of $2-a-d \leq 0$, we obtain $\pi_{2}^{*}=\pi_{2 n}^{*}$; hence, for any $\beta$ we obtain

$$
\pi_{1}^{*}-\pi_{2}^{*}=\frac{\beta^{2}(2-a-4 c+d-(4-a+4 c-d) \beta)}{4(1+\beta)(\beta+(1+\beta) c)((1+\beta)(a+d)-2(a-1))} .
$$

The range of $\beta$ under which $\pi_{1}^{*} \geq \pi_{2}^{*}$ is $\beta \leq(2-a-4 c+d) /(4-a+4 c-d)$. The upper bound of $\beta$ is, however, at most zero because $2-a-d \leq 0, d \in[c, 2 c], 4-a+4 c-d>0$, and $2-a-4 c+d=(2-a-d)-2(2 c-d) \leq 0$. Because $\beta$ must be positive, the supplier negotiates with two buyers in the case of $2-a-d \leq 0$.

The following Proposition summarizes the results that have been obtained so far.

\footnotetext{
${ }^{8}$ Note that one of the solutions for $4(d-c)-2(2-a+4 c-2 d) \beta-(4-a+4 c-d) \beta^{2}=0$ is non-positive because $d \geq c$ and $4-a+4 c-d>0$.
} 
Proposition 2 In the case of $2-a-d>0$, the optimal number of buyers is one if and only if (12) or (13) holds. On the other hand, in the case of $2-a-d \leq 0$, the optimal number of buyers for the supplier is always two.

The condition that the optimal number of buyers is one can be summarized in Figures 1 and 2 .

Figures 1 and 2 here

$* * * * * * * * * * * * * * * * * * * * * * * * *$

We now show the intuition behind Proposition 2. To do this, we focus our discussion on the case in which $\beta \leq(2-a-2 d) /(a-1+d)$, that is, $\pi_{2}^{*}=\pi_{2 p}$. Suppose the investment level $K$ is common under the two cases: one buyer and two pivotal buyers. The net profits in the two cases are represented by

$$
\begin{aligned}
\pi_{1} & =\underbrace{\frac{\beta K+K^{2}}{1+\beta}}_{\text {payment }}-\underbrace{(1+c) K^{2}}_{\text {cost }}=\frac{\beta K-(\beta+(1+\beta) c) K^{2}}{1+\beta}, \\
\pi_{2 p} & =\underbrace{\frac{2\left(\beta K+a K^{2}\right)}{2+\beta}}_{\text {payment }}-\underbrace{(a+d) K^{2}}_{\text {cost }}=\frac{2 \beta K-(a \beta+(2+\beta) d) K^{2}}{2+\beta} .
\end{aligned}
$$

On one hand, for any exogenous parameters, the payment for the supplier (the first terms) is higher when the number of buyers is two than when it is one. On the other hand, the total cost (the absolute values of the second terms) is smaller when the number of buyers is one than when it is two. If the latter part dominates the former part, trading with only one buyer is more profitable. The condition depends on the value of $\beta$ (since we implicitly assume that $a$ and $d$ satisfy $0 \leq 2-a-d$, we do not discuss $a$ and $d$ ). As mentioned earlier, the total costs are not fully compensated by the buyer(s); depending on the bargaining power $\beta$, the buyer(s) and the supplier proportionally divide the gross benefit. When the value of $\beta$ is sufficiently small, the former costs are more important for the supplier than the latter divided benefit. Therefore, when $\beta$ satisfies (12) or (13), the optimal number of buyers is one. 
We can interpret the value of $d / c$ as the degree to which the investment engaged by the input supplier has a firm-specific nature. If $d / c$ is small, the supplier is able to serve a project with a small amount of investment cost, given that it has already incurred sunk investment costs for another project. In other words, it makes it easier for the supplier if the latter investment becomes available for the former project. That is, the investment does not have much of a firm-specific nature. If $d / c$ is large, the converse holds true. That is, it is difficult for the supplier that the latter investment becomes available for the former project. In other words, the investment has a firm-specific nature.

From Figures 1 and 2, we find that the supplier tends to choose a narrow relationship with a single buyer as the value of $d / c$ becomes large. In other words, if the supplier's sunk investment has a firm-specific nature, it negotiates with only one buyer.

We now briefly discuss the investment levels in the two cases: one buyer and two (pivotal) buyers. By a simple calculation, we obtain the following proposition:

Proposition 3 The investment level in the one buyer case $K_{1}$ is larger than that in the two pivotal buyers case $K^{* *}$ if and only if

$$
\beta \leq \min \left\{\frac{2(d-c)}{2-a+2 c-d}, \frac{2-a-2 d}{a-1+d}\right\}
$$

Proposition 3 implies that a narrow buyer-supplier relationship intensifies the supplier's incentive to invest if the supplier's bargaining power is sufficiently weak. As mentioned in the Introduction, until the mid-1970s, nearly 50 percent of subcontractors surveyed reported that prices were "unilaterally determined" by their customers. In other words, the bargaining power of those subcontractors until the mid-1970s was almost equal to zero. Therefore, as pointed out by many researchers who have investigated Japanese buyer-supplier relationships, we can say that the highly specialized relationships between buyers and suppliers in Japan were likely to intensify the specific investments of those firms. 


\section{Decision on the number of trading partners: buyer's de- cision}

Until now, we considered several cases in which the supplier determines the number of buyers. We now consider a case in which a buyer determines the number of buyers. The only difference between the analysis in this section and that in the previous section is the structure of the first stage. Although the number of trading partners is determined by the supplier in the previous section, it is determined by the current buyer in this section.

The discussion is motivated by the following fact. Recently, tn Japanese buyer-supplier relationships, there has been not only an increase in the number of business partners but also a decrease in the degree of suppliers' dependence on major customers (buyers). As small and medium enterprises (SMEs) increase the number of business partners that cooperatively conduct joint R\&D with them, such SMEs tend to succeed in obtaining patents. ${ }^{9}$ In other words, a supplier's technology improves as the number of its trading partners increases. Customers (buyers) can anticipate their suppliers' technological improvements stemming from the diversification of trading partners. The improvements can indirectly benefit those buyers. Therefore, we consider that this discussion is important.

We now consider the buyer's choice concerning the number of buyers. Suppose that the buyer chooses the number to maximize its own profit. Then, the number is one if and only if

$$
\pi_{1}^{b} \geq \begin{cases}\pi_{2 p}^{b} & \text { if } \beta \leq \min \left[\frac{2-a-3 d}{2(a-1+d)}, \frac{2-a-2 d}{a-1+d}\right]=H . \\ \pi_{2 n}^{b} & \text { otherwise. }\end{cases}
$$

Since it is not easy to provide analytical results, we provide several numerical results on the condition that the optimal number of buyers is one (see Figure 3).

Figure 3 here

$* * * * * * * * * * * * * * * * * * * * * * * * *$

\footnotetext{
9 This is mentioned in "2007 White paper on small and medium enterprises in Japan" (Japan small business research institute (2007, p. 233 English version)).
} 
If $a$ is large or $d$ is large (resp. $a$ is small and $d$ is small), the optimal number for the current buyer is one (resp. two). The addition of the supplier's trading partner tends to enhance its incentive to invest because the additional sunk cost $(d-1) K^{2}$ is not large if $d$ is small.

From Figures 1, 2, and 3, we can say that if $d$ is small, the buyer and supplier (the trading partners) tend to agree with the addition of the supplier's trading partner. A lower $d$ means the supplier is able to serve a project with a small amount of investment costs given that it has already incurred sunk investment costs for another project. We consider that such a situation is related to a case in which a supplier has a higher capability of learning from projects with buyers. Therefore, as suppliers accumulate their know-how with regard to engaging in projects with buyers, they tend to increase the number of their trading partners and can then enhance their profitability. This tendency might be consistent with the discussion in Nobeoka et al. (2002), which shows that a broad customer scope strategy leads to superior performance because of learning opportunities.

\section{Concluding remarks}

We provide a simple game-theoretical model and show what factors determine the number of trading partners. We show that when the supplier is able to determine the number of trading partners, the optimal number of trading partners is small for the supplier if the supplier's bargaining power with its trading partners is weak and if the economy of scope concerning the supplier's variable costs is significant. The result might be consistent with

the formation of Japanese buyer-supplier networks and might explain the stylized facts concerning Japanese buyer-supplier networks investigated by many researchers.

In our model, buyers are independent in their final product markets. As discussed in Matsushima (2004, 2008), competition among buyers is an important research topic. To simplify the analysis of our model, we consider the transactions of only one supplier. Considering a market with multiple suppliers is also an important research topic. The wider investigation allows us to discuss competition among suppliers, although this complicates 
the analysis. Moreover, the topic of repeated interactions between suppliers and buyers is also important. This leads us to the following fact: The trading prices in Japanese buyer-supplier relationships gradually decrease over time because of suppliers' technological improvements. These are significant topics for future research. 


\section{APPENDIX}

Sequential bargaining As mentioned in footnote 3, the results in the main text hold even though we consider a sequential bargaining procedure. We consider the following sequential bargaining (see Stole and Zwiebel (1996a, b)): First, the first buyer negotiates with the supplier. If the negotiation reaches an agreement, the buyer's payment $T_{1}$ is determined; otherwise, no transfer occurs and the buyer exits the game. Observing the outcome of the negotiation, the second buyer negotiates with the supplier. If the negotiation reaches an agreement, the buyer's payment $T_{2}$ is determined; otherwise, no transfer occurs and the buyer exits the game.

We first analyze bargaining between the second buyer and the supplier. Given the outcome of the bargaining, we then examine the bargaining among the first buyer and the supplier.

Given that the first buyer's payment $T_{1}$ is determined, we consider the negotiation between the second buyer and the supplier. We need to consider the following two cases: one is the case of $T_{1}>K^{2}$ (the second buyer is non-pivotal) and the other is the case of $T_{1} \leq K^{2}$ (the second buyer is pivotal).

Case 1. $T_{1} \geq K^{2}$. When $T_{1} \geq K^{2}$, the second buyer is non-pivotal. The additional surplus of the trade with the second buyer is $K-(a-1) K^{2}$. The second buyer pays $T_{2}$ to the supplier in a way that satisfies

$$
\beta\left(K-T_{2}\right)=T_{2}-(a-1) K^{2} \text { or } T_{2}=\frac{\beta K+(a-1) K^{2}}{1+\beta} .
$$

Assuming that the second negotiation reaches the agreement mentioned above, the first buyer negotiates with the supplier. It is worth noting that $T_{2}>K^{2}$ holds if and only if the first buyer is also non-pivotal. ${ }^{10}$ Since $T_{2}>K^{2}$ implies $K<\beta /(2+\beta-a), K<\beta /(2+\beta-a)$ must be satisfied for the first buyer to be non-pivotal.

(1.1) If $K \leq \beta /(2+\beta-a)$, the first buyer is non-pivotal and then the additional surplus

\footnotetext{
${ }^{10}$ If $T_{2} \leq K^{2}$, then it depends on the value of $T_{1}$ whether two units of input are supplied by the supplier.
} 
of the trade with the first buyer is $K-(a-1) K^{2}$. The first buyer pays $T_{1}$ to the supplier in a way that satisfies

$$
\beta\left(K-T_{1}\right)=T_{1}-(a-1) K^{2} \text { or } T_{1}=T_{2}=\frac{\beta K+(a-1) K^{2}}{1+\beta} .
$$

This satisfies the condition that $T_{1} \geq K^{2}$ if and only if

$$
K \leq \frac{\beta}{2-a+\beta}(<1)
$$

(1.2) If $K>\beta /(2+\beta-a)$, then the first buyer is pivotal and the additional surplus of the trade with the first buyer is $\left(K-T_{1}\right)+\left(T_{1}+T_{2}-a K^{2}\right)=K+T_{2}-a K^{2}$. The first buyer pays $T_{1}$ to the supplier in a way that satisfies

$$
\beta\left(K-T_{1}\right)=T_{1}+T_{2}-a K^{2} \text { or } T_{1}=\frac{\beta^{2} K+(1+a \beta) K^{2}}{(1+\beta)^{2}} .
$$

This satisfies the condition that $T_{1} \geq K^{2}$ if and only if

$$
K \leq \frac{\beta}{2-a+\beta}(<1)
$$

However, since we now consider the case in $K \geq \beta /(2+\beta-a)$, case (1.2) does not appear in equilibrium.

In every subgame with $T_{1} \geq K^{2}$, if $K \leq \beta /(2-a+\beta)$, then $T_{1}=T_{2}=(\beta K+(a-$ 1) $\left.K^{2}\right) /(1+\beta)$.

Case 2. $T_{1}<K^{2}$. When $T_{1}<K^{2}$, the second buyer is pivotal. The additional surplus of the trade with the second buyer is $\left(K-T_{2}\right)+\left(T_{1}+T_{2}-a K^{2}\right)=K+T_{1}-a K^{2}$. The second buyer pays $T_{2}$ to the supplier in a way that satisfies

$$
\beta\left(K-T_{2}\right)=T_{1}+T_{2}-a K^{2} \text { or } T_{2}=\frac{\beta K+a K^{2}-T_{1}}{1+\beta} .
$$

Assuming that the second negotiation reaches the agreement mentioned above, the first buyer negotiates with the supplier. 
(2.1) If $T_{2} \geq K^{2}$, then the first buyer is non-pivotal and the additional surplus of the trade with the first buyer is $K-(a-1) K^{2}$. The first buyer pays $T_{1}$ to the supplier in a way that satisfies

$$
\beta\left(K-T_{1}\right)=T_{1}-(a-1) K^{2} \text { or } T_{1}=\frac{\beta K+(a-1) K^{2}}{1+\beta} .
$$

Substituting it into $T_{2}$ mentioned above, we obtain

$$
T_{1}=\frac{\beta K+(a-1) K^{2}}{1+\beta}, \quad T_{2}=\frac{\beta^{2} K+(a \beta+1) K^{2}}{(1+\beta)^{2}} .
$$

This satisfies the condition that $T_{1}<K^{2}$ if and only if

$$
\frac{\beta}{2-a+\beta}<K \text {. }
$$

We obtain $T_{2} \geq K^{2}$ if and only if

$$
\frac{\beta}{2-a+\beta} \geq K
$$

There is no value of $K$ that satisfies the inequalities. Therefore, case (2.1) does not appear in equilibrium.

(2.2) If $T_{2}<K^{2}$, then the first buyer is pivotal and the additional surplus of the trade with the first buyer is $\left(K-T_{1}\right)+\left(T_{1}+T_{2}-a K^{2}\right)=K+T_{2}-a K^{2}$. The first buyer pays $T_{1}$ to the supplier in a way that satisfies

$$
\beta\left(K-T_{1}\right)=T_{1}+T_{2}-a K^{2} \Rightarrow \beta\left(K-T_{1}\right)=T_{1}+\frac{\beta K+a K^{2}-T_{1}}{1+\beta}-a K^{2} .
$$

The equation leads to

$$
T_{1}=T_{2}=\frac{\beta K+a K^{2}}{2+\beta}
$$

This satisfies the condition that $T_{1}<K^{2}$ if and only if $\beta /(2-a+\beta)<K$ and $T_{2}<K^{2}$ if and only if $\beta /(2-a+\beta)<K$.

In every subgame with $T_{1}<K^{2}$, if $K>\beta /(2-a+\beta)$, then $T_{1}=T_{2}=\left(\beta K+a K^{2}\right) /(2+\beta)$.

We can summarize the results mentioned above as follows:

$$
T_{1}=T_{2}= \begin{cases}\frac{\beta K+(a-1) K^{2}}{1+\beta} & \text { if } K \leq \frac{\beta}{(2-a+\beta)}, \\ \frac{\beta K+a K^{2}}{2+\beta} & \text { if } K>\frac{\beta}{(2-a+\beta)} .\end{cases}
$$

These transfer payments by the buyers are equal to those derived in section 3.1.2. 


\section{References}

Aghion, P. and Bolton, P., 1992, 'An Incomplete Contracts Approach to Financial Contracting,' Review of Economic Studies, 59, pp. 473-494.

Aghion, P., Dewatripont, M. and Rey, P., 1994, 'Renegotiation Design with Unverifiable Information,' Econometrica, 62, pp. 257-282.

Asanuma, B., 1989, 'Manufacturer-supplier relationships in Japan and the concept of relationspecific skill,' Journal of the Japanese and International Economies, 3, pp. 1-30.

Bala, V. and Goyal, S., 2000, 'A Non-cooperative Model of Network Formation,' Econometrica, 68, pp. 1181-1229.

Belleflamme, P. and Bloch F., 2004, 'Market Sharing Agreements and Collusive Networks,' International Economic Review, 45, pp. 387-411.

Billand, P. and Bravard, C., 2004, 'Non-cooperative Networks in Oligopolies,' International Journal of Industrial Organization, 22, pp. 593-609.

Che, Y.-K. and Hausch, D., 1999, 'Cooperative Investments and the Value of Contracting,' American Economic Review, 89, pp. 125-147.

Chipty, T. and Snyder, C.M., 1999, 'The Role of Firm Size in Bilateral Bargaining: A Study of the Cable Television Industry,' Review of Economics and Statistics, 81, pp. 326-340.

Chung, T.-Y. 1991, 'Incomplete Contracts, Specific Investment and Risk Sharing,' Review of Economic Studies 58, pp. 1031-1042.

Dyer, J.H., 1996, 'Specialized Supplier Networks as a Source of Competitive Advantage: Evidence from the Auto Industry,' Strategic Management Journal, 17, pp. 271-292.

Fisher, M.L., Ramdas, K., and Ulrich, K.T., 1999, 'Component Sharing in the Management of Product Variety: A Study of Automotive Braking Systems,' Management Science 45, pp. 297-315.

Furusawa, T. and Konishi, H., 2007, 'Free Trade Networks,' Journal of International Economics 72, pp. 310-335.

Gaudet, G. and Long, N.V., 1996, 'Vertical Integration, Foreclosure, and Profits in the Presence of Double Marginalization,' Journal of Economics and Management Strategy 5, pp. 409-432.

Grossman, S. and Hart, O., 1986, 'The Costs and Benefits of Ownership: A Theory of Lateral and Vertical Integration,' Journal of Political Economy 94, pp. 691-719.

Goyal, S. and Joshi, S., 2006, 'Bilateralism and Free Trade,' International Economic Review 47, pp. 749-778.

Hart, O. and Moore, J., 1990, 'Property Rights and the Nature of the Firm,' Journal of Political Economy 98, pp. 1119-1158.

Hart, O. and Moore, J. 1999, 'Foundations of Incomplete Contracts,' Review of Economic Studies 66, pp. $115-138$.

Helper, S. and Sako, M., 1995, 'Supplier Relations in Japan and the United States: Are They Converging?,' Sloan Management Review 36, pp. 77-84.

Jackson, M.O. and Wolinsky, A., 1996, 'A Strategic Model of Social and Economic Networks,' Journal of Economic Theory 71, pp. 44-74.

Japan Small Business Research Institute, 2007. '2007 White Paper on Small and Medium Enterprises in Japan,' Ministry of Economy, Trade and Industry. http://www.chusho.meti.go.jp/pamflet/hakusyo/h19/download/2007hakusho_eng.pdf

Jeuland, A.P. and Shugan, S.M., 1983, 'Managing Channel Profits,' Marketing Science 2, pp. 239-272.

Kalai, E. and Samet, D., 1987, 'On Weighted Shapley Value,' International Journal of Game Theory, 16, pp. 205-222. 
Klein, B., Crawford, R. and Alchian, A., 1978, 'Vertical Integration, Appropriable Rents, and the Competitive Contracting Process,' Journal of Law and Economics 21, pp. 297-326.

Konishi, H., Okuno-Fujiwara, M. and Suzuki, Y., 1996, 'Competition through Endogenized Tournaments: An Interpretation of "Face-to-Face" Competition,' Journal of the Japanese and International Economies 10, pp. 199-232.

Kranton, R.E. and Minehart, D.F., 2000, 'Networks Versus Vertical Integration,' RAND Journal of Economics 31, pp. 570-601.

Kranton, R.E. and Minehart, D.F., 2001, 'A Theory of Buyer-Seller Networks,' American Economic Review 91, pp. 485-508.

Matsushima, N., 2004, 'Technology of Upstream Firms and Equilibrium Product Differentiation', International Journal of Industrial Organization, 22, pp. 1091-1114.

Matsushima, N., 2008, 'Vertical Mergers and Product Differentiation', Journal of Industrial Economics, forthcoming.

Nishiguchi, T., 1994, Strategic Industrial Sourcing: The Japanese Advantage, New York: Oxford University Press.

Nobeoka, K., Dyer, J.H, and Madhok, A., 2002, 'The Influence of Customer Scope on Supplier Learning and Performance in the Japanese Automobile Industry,' Journal of International Business Studies, 33, 717-736.

Ramdas, K. and Sawhney, M.S., 2001, 'A Cross-Functional A pproach to Evaluating Multiple Line Extensions for Assembled Products,' Management Science 47, pp. 22-36.

Raskovich, A., 2003, 'Pivotal Buyers and Bargaining Position,' Journal of Industrial Economics, 51, pp. 405-426.

Sato, Y., 1988, Toyota gurupu no senryaku to jissho bunseki (Strategy and Empirical Analysis of the Toyota Group), Tokyo: Hakuto Shobo.

Segal, I. 1999, 'Complexity and Renegotiation: A Foundation for Incomplete Contracts,' Review of Economic Studies 66, pp. 57-82.

Shapley, L.S., 1953, 'Additive and Non-additive Set Functions,' Ph.D. thesis, Princeton University, Princeton, 1953.

Stole, L.A. and Zwiebel, J., 1996a, 'Intra-firm Bargaining under Non-binding Contracts,' Review of Economic Studies, 63, pp. 375-410.

Stole, L.A. and Zwiebel, J., 1996b, 'Organizational Design and Technology Choice under Intrafirm Bargaining,' American Economic Review, 86, pp. 195-222.

Williamson, O. 1979, 'Transaction-Cost Economics: the Governance of Contractual Relations,' Journal of Law and Economics 22, pp. 233-262. 


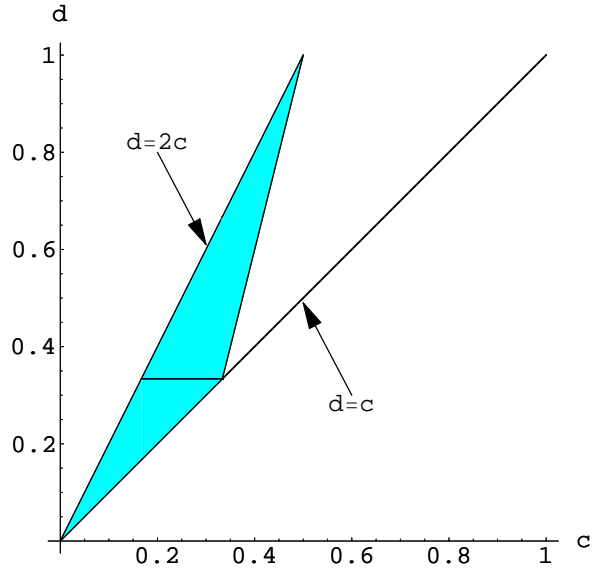

$\beta$ is sufficiently small

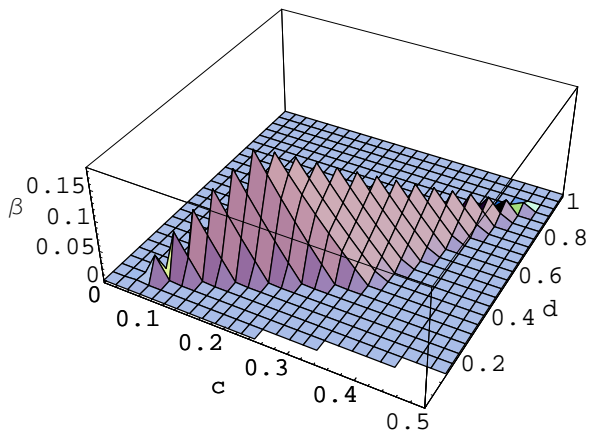

The upper bound of $\beta$

Figure 1: The optimal number of buyers is one $(a=1)$.

[Colored region: the optimal number is one] 


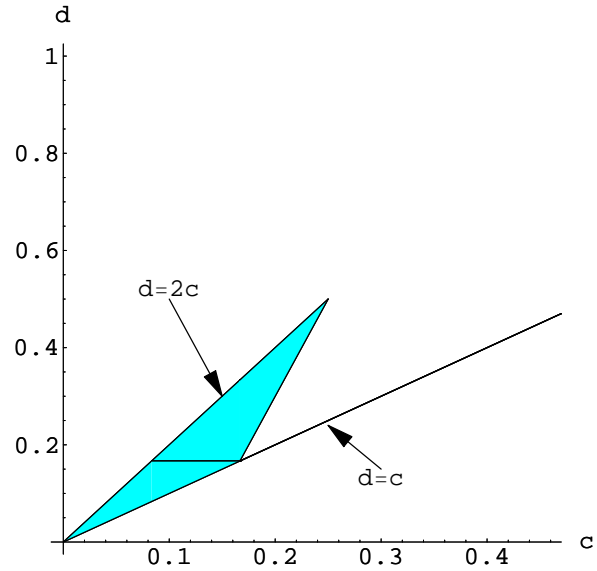

$\beta$ is sufficiently small

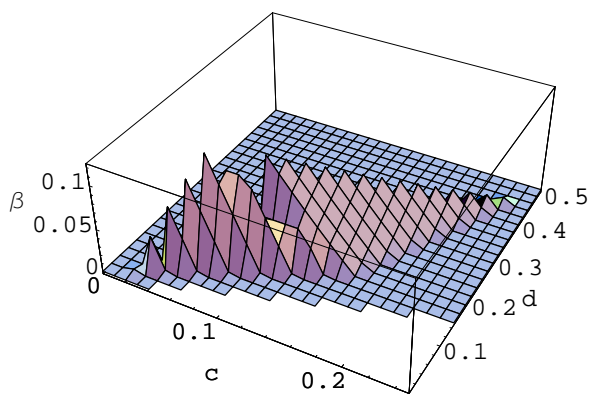

The upper bound of $\beta$

Figure 2: The optimal number of buyers is one $(a=1.5)$. [Colored region: the optimal number is one] 

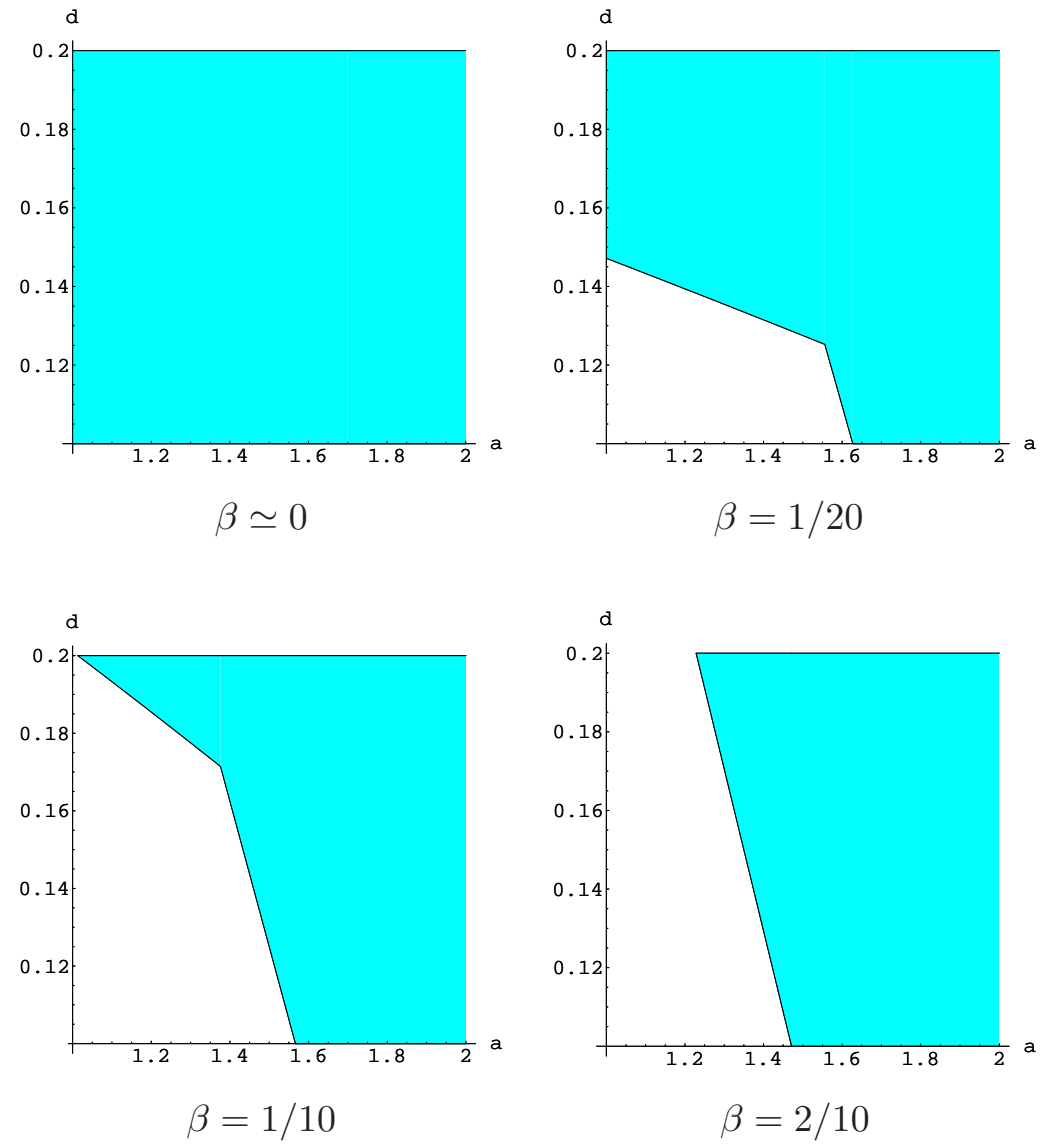

Figure 3: The optimal number of buyers is one for the buyer $(c=1 / 10)$. [Colored region: the optimal number is one, White region: the optimal number is two] 